\title{
A Respeito da Estruturação de Dissertações e Teses em Administração
}

Moema Miranda de Siqueira

O artigo de Pedro Lincoln Mattos me instigou, fazendo-me aceitar a proposta para comentá-lo.

O interesse se originou da denúncia do excesso de zelo pelo método que atinge hoje os trabalhos de dissertação e tese em Administração. O formalismo que decorre dessa postura é provavelmente bastante responsável pelas modestas contribuições ao conhecimento que em geral esses estudos obtém. As exigências e o puro rigor metodológico, assim como a familiaridade com técnicas estatísticas, não só pretendem assegurar o caráter científico, como ajudam a apresentar o problema estudado com certa sofisticação, que muito agrada à academia. As críticas freqüentes aos instrumentos utilizados e a dados trabalhados de forma insatisfatória, quase sempre se restringem aos aspectos metodológicos.

Desde 1994, Bertero e Keinert haviam identificado em estudos organizacionais brasileiros propostas científicas mais empiricistas que de construção teórica. O estudo de Carrieri e Luz (1998) sobre dissertações da UFMG nas áreas de Sociologia, Ciência Política, Administração, Educação, Economia/Demografia, constatou que as pesquisas privilegiavam a construção de variáveis para a explicação dos fatos, hipóteses e medição das relações entre fatos. Ainda quando optavam por paradigma interpretativo, buscavam alternativas empíricas para identificar os métodos que os indivíduos usavam para dar sentido e, ao mesmo tempo, construir suas ações gerenciais cotidianas. As pesquisas que pretendiam adotar uma análise mais dialética, segundo os autores do estudo, acabavam usando referências funcionalistas e explicações racionais. Martins (1997) encontrou o mesmo predomínio das abordagens empírico-analíticas nas teses e dissertações defendidas entre 1980/1993 em três programas de pós-graduação de São Paulo (FEA/USP, EAESP/FGV e FEA/PUC).

Esse vício, contudo, não é exclusivo da administração, perpassando diferentes disciplinas, fruto do paradigma epistemológico da modernidade, racionalizante e especialista.

Já há algum tempo, as críticas a essa postura vêm sendo debatidas, propondose perspectivas mais inclusivas e abrangentes. A complexidade ressaltada na 
visão pós-moderna obriga à superação das análises particularizadas, preconizando a inter e até a transdisciplinaridade.

Para mim, na Administração, tal problemática é agravada por um dilema. De um lado, a formação de seu corpo teórico, que só se consolidou a partir da contribuição de múltiplas disciplinas, de diferentes ramos do conhecimento, conduz naturalmente a uma visão menos especializada de seu complexo objeto de estudo. Além disso, sua configuração como ciência social aplicada acaba levando à busca de tendências e generalizações que facilitem sua ação instrumental.

Concordo com o Professor Pedro Lincoln que esta dicotomia é uma questão paradigmática, não se confundindo com opções metodológicas.

A discussão sobre separação teoria e prática parece há algum tempo ultrapassada pela epistemologia (filosofia da cidência) e por muitos dos analistas da teoria de organizações. Como bem ressaltam Mardsen e Townley (2001, p. 31), na Introdução do volume 2 do Handbook de Estudos Organizacionais, "prática” é um constructo teórico e a teorização é, em si mesma, uma prática”. A Teoria Organizacional não só reflete a prática organizacional como ajuda a construir essa prática.

É verdade que o relativismo do pós-modernismo, ao defender a impossibilidade de uma observação teoricamente neutra, acabou reduzindo a confiança no trabalho empírico, a favor da segurança relativa da teoria. O interesse crescente pelas mudanças que estão ocorrendo na sociedade, como as novas formas organizacionais e as novas experiências de espaço e tempo, fazendo com que o passado deixe de ser uma referência segura para o futuro, impõe múltiplas e até conflitantes leituras. Isto, ao estimular o dissenso, a discussão e a argumentação, parece atender mais de perto ao desenho projetado pelo Prof. Pedro Lincoln Mattos para as dissertações e teses em Administração.

No entanto, as revisões sobre os estudos organizacionais, dentro e mesmo fora do Brasil, que se tornaram freqüentes na década de 90, constatam que a maioria continua dominada pela ortodoxia positivista, contribuindo apenas com acréscimos conceituais e teóricos às estruturas de conhecimento existentes. Produção "periférica, epistemologicamente falha, metodologicamente deficiente, sem originalidade e prática, em grande escala, mimetismo mal informado" (Bertero, Caldas e Wood, 1999). Os trabalhos são freqüentemente ilustrativos ou descritivos, sem pretensões de uma construção indutiva de conhecimento. Os pressupostos da teoria normal, respondendo mais de perto aos interesses dominantes, dificultam qualquer mudança de paradigma.

Concordo que a angústia que normalmente acomete os autores na fase de produção de dissertações e teses, pode levar a uma sofisticação inadequada da- 
queles trabalhos, valorizando a forma em prejuízo do conteúdo. Costumo interpelar orientandos e mesmo alunos em bancas das quais participo sobre o excessivo referencial teórico, muitas vezes sem compatibilização direta com o próprio objetivo da dissertação ou tese, a não ser quando a mesma pretenda ser uma grande revisão do estado da arte no tema proposto. No entanto, tendo a ser condescendente nas dissertações de mestrado, considerando a etapa de formação acadêmica do aluno, o tempo e esforço despendido nas pesquisas bibliográficas e o momento ritualístico que essa produção ainda representa. A citação de Kuhn confirma essa assertiva: teses e dissertações são rituais de entrada e de maturidade nas academias.

Voltando à pretensão do autor do documento de que elas se constituam em espaços da "arte argumentativa para fazer avançar o conhecimento", me parece ainda um pouco utópico, pelo menos no que se refere às dissertações. Uma das dificuldades, além das já apontadas, segundo meu modo de ver, são os critérios de avaliação que fundamentam os pareceres de recomendação e reconhecimento dos programas de pós-graduação. O prazo de duração dos cursos de mestrado, fixado em dois anos, e do doutorado, em quatro anos, e o conseqüente indicador de terminalidade (número de dissertações e teses defendidas no prazo), é um limitante às características atuais de nossas dissertações e teses. Houve, até mesmo, da parte da CAPES, sob o argumento de que nossas dissertações eram mais complexas e robustas do que aquelas da maioria dos programas de pósgraduação de outros países, uma sugestão para que esses trabalhos fossem simplificados.

A grande dependência dos estudos organizacionais a uma gama de disciplinas, de diferentes naturezas e objetos, impondo múltiplas e até conflitantes leituras, torna imensamente complexa a tarefa de "fazer avançar o conhecimento". Mesmo, ou talvez justamente por isso, aceita-se a afirmação de Popper (1974), citada pelo Prof. Pedro Lincoln, de que o conhecimento preferível não é o certo, mas o limite onde pudermos chegar. Isto pode ser a explicação para o que se constata, como fizeram Bertero e Keinert (1994), em relação à opção preferencial na produção acadêmica brasileira por estudos "mais empiricistas do que por construções teóricas”. Embora a confiança no trabalho empírico tenha sido abalada pelo relativismo pós-modernista, com o receio da contaminação e pelo reconhecimento da impossibilidade de uma observação teoricamente neutra, e apesar do grande charme da ciência organizacional contranormal e seus temas centrais (poder, cultura, tempo, espaço, estética, emoção...), parece menos arriscado àqueles da área de gestão atolados na sempre dura tarefa de dissertação ou tese, embrenharem-se pelo caminho da evidência e da racionalidade.

Da mesma forma, linhas de inspiração estrangeira, com predomínio absoluto de referências bibliográficas de outros países, principalmente Estados Unidos, refle- 
tem tanto a exigência dos próprios programas - e da CAPES em nível superior para que conste na bibliografia consultada autores estrangeiros, como certo preconceito contra nossa produção própria. Enquanto esses critérios não forem discutidos e revistos, continuaremos consumidores e não produtores originais de teorias e conceitos, sem as devidas "reduções sociológicas "cada vez mais necessárias a alternativas de gestão auto-sustentadas.

Por outro lado, a visão de que a teoria diz respeito ao pensamento e reflexão, enquanto a prática refere-se à ação, ao mundo real, quase como antítese à teoria, ainda perturba alguns estudiosos da área de gestão. Existe mesmo um certo pudor de se envolver com as questões práticas. Uma das razões, já bem ressaltada, é que, embora a Teoria Organizacional seja essencialmente teoria de gestão, "fala mais e prescreve mais para quem gerencia e muito pouco dos que são gerenciados”. A ciência social contranormal é uma tentativa de reincorporar à análise as características da afetividade humana "que escapam aos cálculos”.

Já existe bastante concordância sobre o risco da razão sozinha ser a única referência para a prática organizacional. Considera-se indispensável a introdução de regras de convivência ética, limites do respeito entre os participantes, valores que orientem o quotidiano entre as pessoas na organização, reconhecendo e legitimando o espaço da afetividade e definindo o locus do relacionamento teoria/prática.

Talvez assim se concretize o desejo do autor que ora comento, de que os autores de nossas dissertações e teses tenham mais o que dizer e se sintam menos obrigados a dizer alguma coisa. Poderá ainda reduzir a proporção daqueles estudiosos da Administração que, conforme constatado por Bertero, sentem-se pouco à vontade em escolas ou departamentos de Administração, preferindo abrigar-se em grupos de outras ciências sociais.

\section{RefERÊNCIAS BibLIOgRÁficas}

\section{BERTERO, C. O.;}

CALDAS, M. P.;

WOOD, T.

Produção científica na área de administração de empresas: provocações, insinuações e contribuições para um debate local. Revista de Administração Contemporânea, v. 3, n. 1, p. 147-178, jan./abr. 1999.
BERTERO, C. O.;

KEINERT, T. M. M.

A evolução da análise organizacional no Brasil (1961-93). Revista de Administração de Empresas, v. 34, n. 3, p. 81-90, maio/ jun. 1994. 
CARRIERI, A. DE P.;

LUZ, T. R.

Paradigmas e metodologias: não existe pecado do lado de baixo do equador. In: ENCONTRO ANUAL DA ANPAD, 20., 1998, Foz do Iguaçú. Anais... Foz do Iguaçú: ANPAD, 1998. 1 CDROM.

MARDSEN, R.;

TOWLEY, B.

Introdução - a coruja de Minerva: reflexões sobre a teoria na prática. In: CALDAS, M.; FACHIN, R.; FISCHER, T.
Handbook de estudos organizacionais. São Paulo: Atlas, 2001. v. 2.

MARTINS, G. DE A.

Abordagens metodológicas em pesquisas na área de administração. Revista de Administração de Empresas, v.32, n. 3, p. 5-12, jul./set. 1997.

POPPER, K.

Replies to my critics. In: SCHILPP, P. The philosophy of Karl Popper. La Salle, v. 2, p. 961-1197, 1974. 